\title{
Sasana Beladiri Interaktif: Pamer Tarung
}

\author{
Galang Parendra Wastudiawan dan Vincentius Totok Noerwasito \\ Departemen Arsitektur, Fakultas Teknik Sipil dan Perencanaan, Institut Teknologi Sepuluh Nopember (ITS) \\ e-mail: vtonoer@arch.its.ac.id
}

\begin{abstract}
Abstrak - Beladiri sebagai salah satu olahraga yang mempunyai potensi menghasilkan prestasi kurang mendapat perhatian, termasuk dalam sisi fasilitas. Hal ini sebagai dampak tidak populernya olahraga tersebut. Kurangnya akses membuat pengetahuan masyarakat pada beladiri sangat kurang. Mereka masih melihat beladiri sebagai sebuah hal yang identik dengan kekerasan sehingga kurang diminati, padahal hakekat beladiri adalah untuk melindungi diri, bukan untuk kekerasan. Kurangnya minat menyebabkan proses regenerasi pada beladiri menjadi terhambat. Dengan menggunakan metode Rationalist Approach dan pendekatan perilaku, objek rancang bukan hanya memfasilitasi beladiri, namun juga mempunyai tujuan untuk merubah paradigma masyarakat. Objek rancang berupa sasana beladiri yang juga memiliki fungsi edukasi. Tempat latihan bagi atlet dapat diakses secara visual oleh masyarakat umum sehingga mereka bisa melihat kegiatan yang sebenarnya dari beladiri tersebut sehingga pola pikir tentang beladiri mereka bisa berubah. Kesadaran tentang beladiri masyarakat juga dimunculkan lewat bentukan yang ada. Sehingga objek desain bukan hanya mewadahi pelaku beladiri, namun dapat meningkatkan minat masyarakat untuk berpartisipasi aktif.
\end{abstract}

Kata Kunci_Olahraga, Prestasi, Beladiri, Minat, Edukasi.

\section{PENDAHULUAN}

B ERBAGAI cara dilakukan pemerintah Indonesia untuk meningkatkan prestasi olahraga Indonesia. Namun yang terjadi dilapangan adalah sebuah kesenjangan terhadap beberapa olahraga tertentu. Menurut data yang dihimpun oleh Badan Pusat Statistik RI 2014, ketersediaan fasilitas cenderung kepada cabang olahraga yang lebih diminati masyarakat, seperti sepak bola, voli, dan bola basket bukan kepada cabang olahraga yang lebih berpotensi.

Beladiri menjadi salah satu olahraga yang seharusnya menjadi salah satu titik fokus pembanguann. Ada beberapa alasan diantaranya; Beladiri mempunyai banyak macam cabang yang bisa dikembangkan. Indonesia memiliki olahraga beladiri khas yang menjadi tanda bahwa olahraga ini cocok dengan karakter masyarakat Indonesia. Dan juga sudah banyak presatasi olahraga beladiri para atlet Indonesia di tingkat Internasional.

Namun permasalahannya beladiri merupakan olahraga yang kurang diminati masyarakat. Mereka memilih pasif sebagai penonton daripada terlibat aktif di dalamnya. Hal tersebut terjadi karena beberapa faktor. Yang pertama adalah karena kurangnya fasilitas khusus beladiri. Padadahal menurut data dari BPS RI pada Susenas 2012, akses utama masyarakat untuk mengenal beladiri adalah dengan melalui kalur perguruan dan perkumpulan beladiri. Karena ketidakjelasan tempat dan waktu, maka eksistensi mereka di masyarkat menjadi berkurang.

$\begin{aligned} & \text { Persentase Desa/Kelurahan yang Memiliki Fasilitas Lapangan/Gelanggang } \\
& \text { Olahraga Menurut Jenis Olahraga, 2003-2014 }\end{aligned}$
\begin{tabular}{|cccccc}
\hline \multicolumn{5}{c}{ Olahun } \\
JenisOlahraga & 2003 & 2005 & 2008 & 2011 & 2014 \\
& $(2)$ & $(3)$ & $(4)$ & $(5)$ & $(6)$ \\
\hline Bola Voli & 79,54 & 79,35 & 78,09 & 68,15 & 66,89 \\
\hline Sepak Bola & 53,94 & 57,95 & 56,19 & 50,50 & 54,38 \\
Bulu Tangkis & 46,05 & 47,25 & 49,34 & 43,74 & 42,34 \\
\hline Bola Basket & 5,31 & 6,70 & 7,10 & 6,27 & 6,08 \\
\hline Tenis Lapangan & 4,96 & 5,03 & 5,10 & 4,55 & 4,21 \\
\hline Renang & 1,51 & 2,61 & 2,58 & 4,85 & 2,65 \\
\hline
\end{tabular}

Sumber: BPS RI - Statistik Podes 2003, 2005, 2008, 2011, dan 2014

Gambar 1. Statistik Ketersediaan fasilitas Olahraga

Sumber: BPS RI

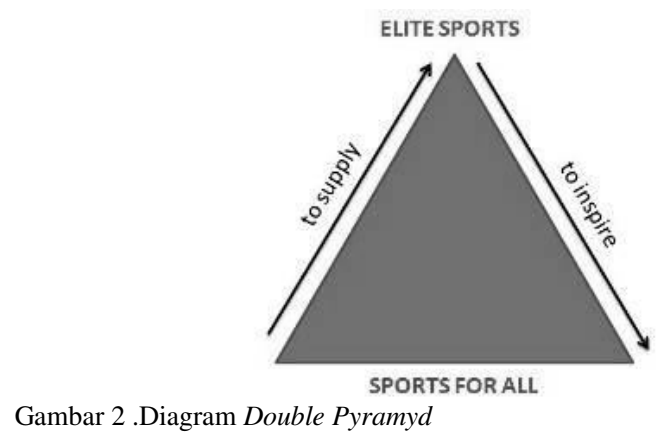

Sumber : detik.com

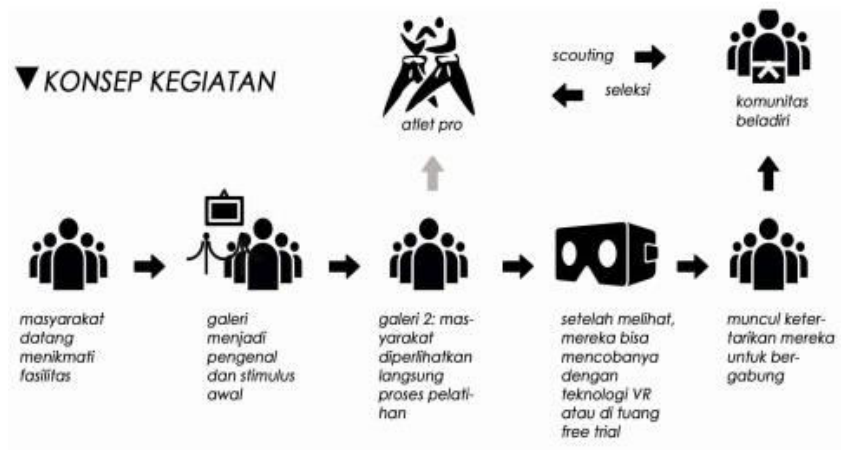

Gambar 3. Konsep Interaksi Kegiatan

Sumber : Dokumentasi Pribadi

Yang kedua adalah banyaknya program-program di TV yang menampilkan gerakan-gerakan beladiri. Karena pengetahuan yang kurang, banyak orang yang cenderung meniru adegan beladiri tanpa pengawasan ahli yang menyebabkan terjadinya hal yang tidak diinginkan terjadi.

Yang terakhir adalah mengenai stigma beladiri yang keras. Banyak masyarakat yang malas menerima pelatihan yang keras. Sering sekali terdapat cedera saat latihan. Pada akhirnya banyak yang menganggap bahwa beladiri merupakan olahraga yang menyusahkan dan menyakitkan sehingga dihindari oleh masyarakat. 


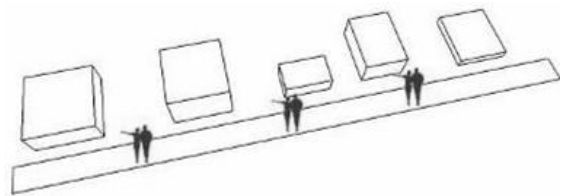

Gambar 4. Diagram bentuk 1 Galeri Konvensional Sumber : Dokumentasi Pribadi

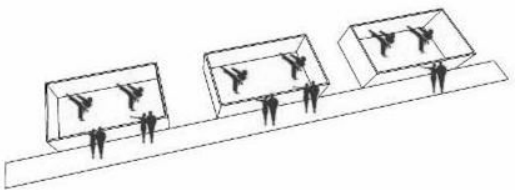

Gambar 5. Diagram bentuk 2 Etalase Latihan Beladiri Sumber : Dokumentasi Pribadi

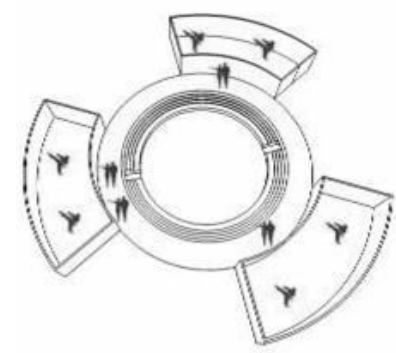

Gambar 6 .Diagram bentuk 3 Penyatuan Bentuk Dengan Arena Sumber : Dokumentasi Pribadi

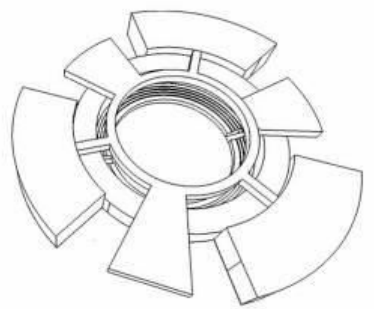

Gambar 7 . Diagram Bentuk 4 Penambahan Program dan Bentuk Final.

\section{KAJIAN PUSTAKA}

Karena itu, "Sasana Beladiri Interaktif: Pamer Tarung" ini menjadi solusi adanya permasalahan yang sudah dijelaskan di atas. Desain yang ada bukan hanya berfungsi sebagai wadah bagi pelaku beladiri, namun juga mempunyai fungsi edukatif kepada masyarakat. Interaksi antara pelaku beladiri dan masyarakat umum diharapkan dapat merubah paradigma masyarakat mengenai beladiri kembali ke hakekatnya, yaitu sebagai self defence. Dengan begitu minat mereka untuk terlibat langsung di olahraga beladiri bisa meningkat.

Interaksi pada tulisan ini mengacu pada interaksi menurut Dr. Maarten van Bottenburg dalam Paper for World Sports for All Congres, ia menyatakan bahwa olahraga dapat dikategorikan menjadi dua jenis menurut siapa pelakuinya dan apa tujuan olahraga tersebut. Yang pertama adalah Sports for All yang merupakan olahraga yang diperuntukkan untuk semua orang. Tujuan dari olahraga ini adalah untuk hiburan, hobi, dan kesehatan. Yang kedua adalah Elite Sports yang bisa kita katakan adalah atlet. Tujuan dari rlite sports adalah meraih prestasi.

Sports for All dan Elite Sports tidak dapat dipisahkan begitu saja. Ada interaksi saling ketergantungan diantara
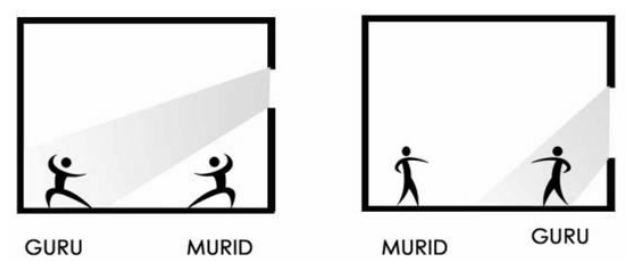

Gambar 8 . Konsep Ruang Latihan

Sumber : Dokumentasi Pribadi

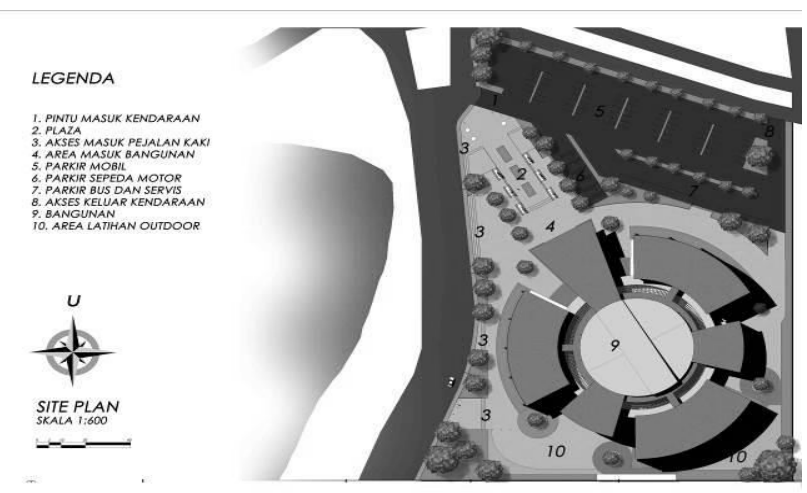

Gambar 9. Site Plan

Sumber : Dokumentasi Pribadi

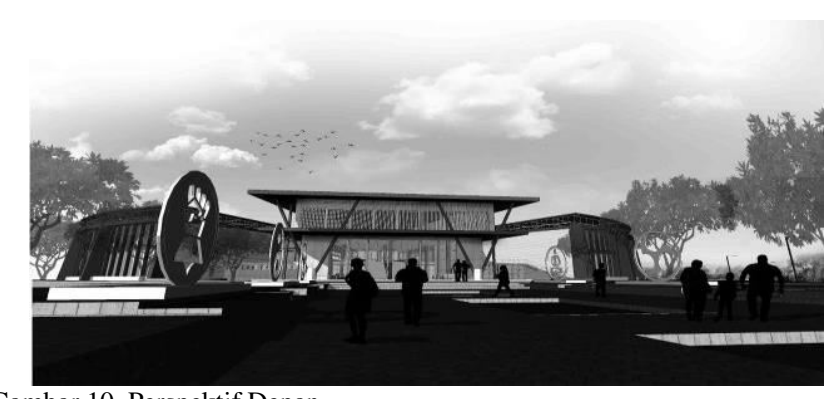

Gambar 10 .Perspektif Depan

Sumber : Dokumentasi Pribadi

keduanya. Elite Sports berperan sebagai media inspirasi bagi masyarakat untuk berolahraga sedangkan Sports for All berfungsi sebagai penyedia sumber daya atlet profesional.

\section{METODA PERANCANGAN}

Pendekatan yang digunakan adalah pendekatan perilaku atau behaviour. Tujuan utama dari desain salah satunya adalah untuk merubah persepsi masyarakat mengenai beladiri. Untuk itu teori perubahan perilaku dibutuhkan. Dalam buku berjudul 7 Habbits for Highly Effective People karya Stephen R. Covey dijabarkan bahwa untuk merubah perilaku manusia maka yang harus diubah adalah paradigma mereka. karena itu untuk mengubah perilaku masyarakat agar lebih meminati beladiri, maka paradigma mereka yang salah terhadap beladiri harus diubah.

Sedangkan Penelitian Rogers (1974) mengungkapkan bahwa sebelum orang mengadopsi perilaku baru (berperilaku baru), didalam diri orang tersebut terjadi proses yang berurutan, yakni.

1. Awareness (kesadaran), yakni orang tersebut menyadari dalam arti mengetahui setimulus (objek) terlebih dahulu. 
2. Interest, yakni orang mulai tertarik kepada stimulus.

3. Evaluation (menimbang - nimbang baik dan tidaknya stimulus bagi dirinya).Hal ini berarti sikap responden sudah lebih baik lagi.

4. Trial, orang telah mulai mencoba perilaku baru.

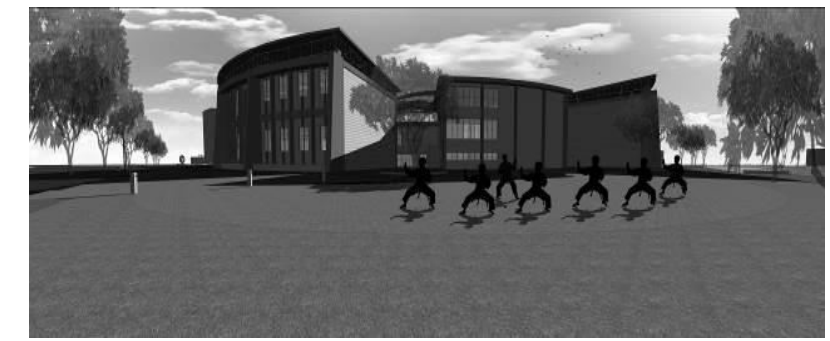

Gambar 11 .Galeri Pamer tarung

Sumber : Dokumentasi Pribadi

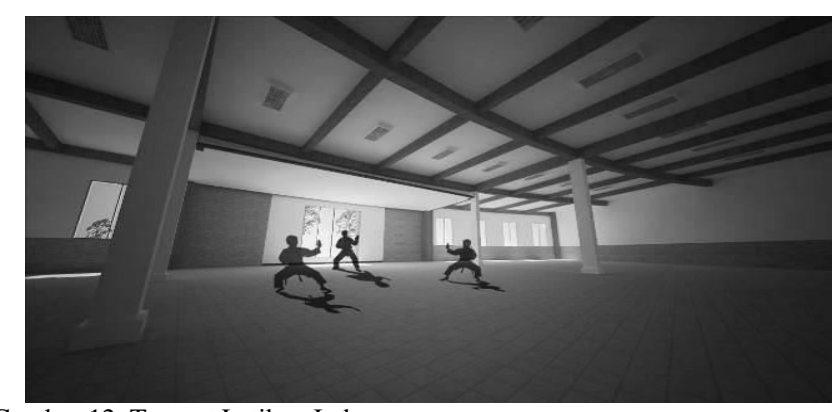

Gambar 12. Tempat Latihan Indoor

Sumber : Dokumentasi Pribadi

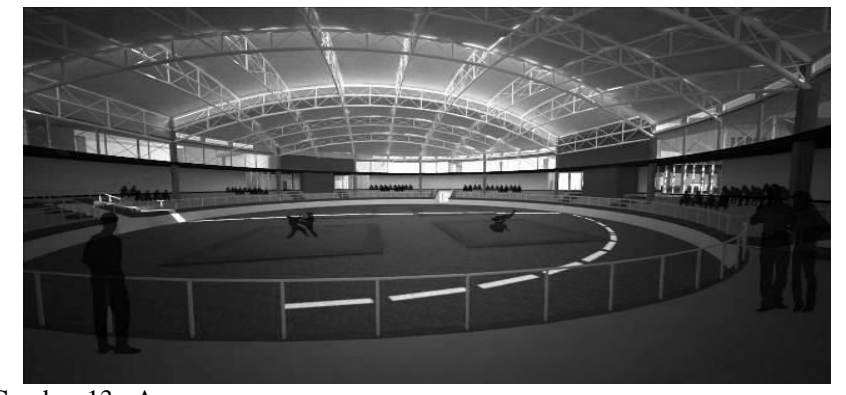

Gambar 13 . Arena

Sumber : Dokumentasi Pribadi

Penulis menggunakan metoda Rationalist Approach yang diambil dari buku Basic Design Methods karya Kari Jormakka. Ada dua tahapan mendesain dalam matode ini; yang pertama adalah Performance Form (Bentuk Kinerja). Dalam fase ini hal yang harus dilakukan adalah menentukan fungsi bangunan secara jelas dahulu agar bentukan yang tercipta optimal. Setelah fungsi didefinisikan, tahap selanjutnya adalah Design Research (Riset Desain) yang merupakan tahap dimana telah ditemukannya permasalahanpermasalahan dan solusi dari fungsi-fungsi yang telah ditentukan. Pemecahan masalah ini nantinya dijadikan sebuah kesatuan yang utuh.

\section{KESIMPULAN}

Permasalahan utama dari objek rancang ini adalah bagaimana dapat mengubah paradigma masyarakat mengenai beladiri. Cara yang dilakukan adalah dengan memberi wadah interaksi bagi masyarakat dan atlet. Fasilitas latihan yang ada menjadi semacam etalase yang dapat diakses secara visual oleh masyarakat umum. Masyarakat umum dapat melihat secara langsung bagaimana proses pelatihan dan semua kegiatan para atlet dan pelaku beladiri di dalamnya. Selain itu, tempat latihan menganut prinsip dojo yang mempunyai kesan sakral sehingga bukan hanya atlet, masyarakat umum juga dapat merasakan pengalaman ruang yang sama pula. Bentukan dari proses desain menghasilkan bentukan yang melambangkan beberapa hal dalam beladiri yaitu orang dalam posisi kuda-kuda. Hal tersebut juga berfungsi untuk meningkatkan kesadaran masyarakat akan beladiri. Diharapkan minat masyarakat untuk terjun langsung dalam bidang ini semakin meningkat

\section{HASIL DAN EKSPLORASI}

Objek rancang merupakan sebuah fasilitas yang menampung khusus olahraga beladiri. Fasilitas ini mempunyai fungsi sebagai tempat berkumpul, berlatih, serta bertanding bagi para pelaku beladiri. Namun tidak sebayas itu, desain juga mampu menjadi sarana edukasi bagi masyarakat untuk mendalami lebih dalam mengenai olahraga ini.

Fasilitas utama yang ada didasarkan pada pelaku utama yang ada dalam desain yaitu atlet/perkumpulan beladiri dan juga masyarakat umum. Karena itu desain juga harus mengakomodasi interaksi antara kedua pelaku utama tersebut. Interaksi ini didasarkan pada diagram Double Pyramyd dari Dr. Marteen van Bottenburg yaitu masyarakat umum (sport for all) sebagai sumber daya utama munculnya bibit-bibit unggu dalam bidang olahraga sedangkan atlet (elite sport) berfungsi sebagai inspirator.

Karena itu, konsep utama adalah desain nantinya bagaimana menggabungkan dua fasilitas utama para pelaku agar terjadi interaksi antara mereka. Cara yang dapat dilakukan adalah dengan membuat fungsi galeri pada bangunan tersebut. galeri yang ada mempunyai etalase-etalase unik yaitu berupa tempat-tempat latihan bagi para pelaku beladiri. Galeri tersebut dinamakan galeri Pamer Tarung karena menampilkan kegiatan langsung dari para atlet. Dengan begitu diharapkan masyarakat dapat melihat langsung bagaimanakah kegiatan-kegiatan beladiri itu sebenarnya disana.

Untuk semakin membuang jauh kesan kasar dan brutal pada beladiri, maka cara kedua yang dilakukan adalah dengan membuat desain ruangan yang mendukung. Pada zaman dahulu orang-orang yang datang belajar beladiri untuk mencari pencerahan dan diselingi langsung untuk beribadah sehingga ruangan yang ada harus bersifat sakral. Hal ini diimplementasikan dengan mengambil preseden bangunan dojo di Jepang dimana penempatan posisi guru dan murid diatur sedemikian rupa. Posisi guru diletakkan di tempat yang diterangi cahaya. Hal ini menjadi sebuah simbol bahwa murid datang masih dalam keadaan tersesat (di tempat gelap) untuk mencari penerangan pada diri gurunya. Sehingga bukan hanya pelaku beladiri yang mendapatkan pengalaman ruang tersebut, masyarakat di galeri juga mendapatkannya.

Untuk bentuk sendiri didasarkan pada gabungan tiga fasilitas utama bangunan yaitu tempat berlatih, galeri, dan tempat bertanding yang diolah dan dikonfigurasikan sehingga menjadi bentukan yang efektif. Bentukan yang ada juga dapat 
menjadi metafora dari seseorang yang melakukan posisi kudakuda. Dan pada rancangan tapaknya, penulis mengaturnya semaksimal mungkin agar potensi tapak yang ada dapat termaksimalkan.

\section{DAFTAR PUSTAKA}

[1] Jormakka, Kari. Basic Design Methods. 2007. Birkhäuser Architecture

[2] Van Bottenburg, Marteen. (2002, October). Sport for All and Elite Sport: Do They Benefit One Another?. W.J.H Mulier Institute

[3] Neufert, Ernst. (2002). Data Arsitek Edisi 33 Jilid 2. PT Gelora Aksara Pratama
[4] D. Glenniza. (2015, October). Strategi Olahraga Yang Membawa Kesuksesan. Available: http://sport.detik.com/aboutthegame/read/2015/10/28/080246/3055123/1 497/strategi-kebijakan-olahraga-yang-membawa-kesuksesan

[5] Sturzebecher, Peter, dan Sigrid Ulrich. 2002. Architecture of Sports: New Concepts and International Projects for Sports and Leisure. West Sussex: Willey-Academy

[6] Tandal, Anthonius, dan Pingkan Egam. 2011. Arsitektur Berwawasan Perilaku (Behaviourisme). Available: http://ejournal.unsrat.ac.id/index.php/jmm/article/viewFile/314/239

[7] Culley, Peter, and John Pacoe. (2009). Sport Facilities and Technologies. Routlegde Taylor and Francis Group 